\title{
Pilgrimage: Intrinsic Motivation and Active Behavior in the Eldery
}
Authors' contribution:
A) conception and design of the study
B) acquisition of data
C) analysis and interpretation of data
D) manuscript preparation
E) obtaining funding

\author{
$\underline{\text { Henning Eichberg }}^{1 \text { A-C,E }}$, Jerzy Kosiewicz ${ }^{1 \text { A,C-E }}$, Danilo \\ Contiero $^{3 \mathrm{~A}, \mathrm{~B}, \mathrm{D}, \mathrm{E}}$ \\ ${ }^{1}$ SDU University, Odense, Denmark \\ ${ }^{2}$ Josef Pilsudski University of Physical Education in Warsaw, Poland \\ ${ }^{3}$ University of Rome, Foro Italico, Italy
}

ABSTRACT

Can intrinsic religious motivation have relevant effects on the motor activity of older
people? How are processions and pilgrimages related to the dominant imagination of
old age as a period of fatigue and gray hair, suffering and loneliness, retirement and
rest - and of waiting: waiting for a call from a loved one, waiting for the visit of a good
companion, or, finally, expecting the end of life?
This study is based on interviews with people from different countries, cultures, and
religions.
They show that a pilgrimage can push the elderly to do physical activities of some
importance that are at the same time related to some sort of religious motivation.
The pilgrim's walking in itself, as well as the achievement of its goal, helps people to
reconsider their quality of life and active behavior. Elderly people also experience their
independence, which perhaps was considered to be lost, with a pilgrimage, giving a
new meaning to their aging. In light of these activities, old age becomes a period not
just of physical and mental decay, but of self-discovery. It becomes an age that allows
one to do something that one has not done during one's youth. And pilgrimages give
people time to discover themselves - they have the chance to work on their own
personality and social identity. This contributes to the understanding of their health and
of their quality of life in a deeper sense.
health, aging, movement, religion, spirituality KEYWORDS

\section{Old age and religion - preliminary remarks}

In a place of worship of whatever religion, one may observe that most of the people attending the ceremony are old. At first sight, the reason for this phenomenon can be seen in the physical decline of elderly people and their concerns about their "spiritual health."

Seen from a social point of view, attending the services in one's parish and taking part in religious celebrations is an important part of the social life of the elderly. Home life and school are important places of socialization in youth, while the workplace later takes this position; likewise, people in retirement may find the parish or other places of religious worship as a social environment.

Pilgrimages are a part of the parish activity (Kosiewicz 2004, pp. 407-416), and most participants are older members. 
Basically, these activities are spiritually motivated, but they have other benefits for social life and quality of life. For participants who are no longer able to drive or who do not have other people to support them, a pilgrimage can be an opportunity to return to travel, socializing, and rediscovering themselves.

The question of this study is as follows: How are spiritual motivations and the practical pilgrimage related to elderly people's social life and active behavior?

\section{Interdisciplinary approach and method}

The following study will not be focused on religion as an idea with spiritual meaning, but rather about psychological wellness, which may nonetheless be connected with religion and spirituality.

Older people on various pilgrimages have the opportunity to socialize and meet the young people and young volunteers who take care of them. This may enable them to feel good, rather than feeling excluded, which can sometimes happen in an everyday social context; they can rediscover an openness to life and its possibilities. The method of doing interviews does not necessarily provide rigorous data, but it does allow the subjects to talk first-hand about their experiences and emotions. By configurational analysis, the space, time, relationships, and energy of pilgrimages can be made visible. The interviewees have chosen a certain time for their walking that coincides with old age and with a period of discovering themselves.

\section{Interdisciplinary approach - Maslow}

According to Maslow's theory of needs, people have a hierarchy of needs to satisfy.

People start to satisfy the lowest level of needs and then continue to the top. People are able to satisfy the next level of needs only when they have satisfied all the needs of the previous one (Maslow 1943).

The theory of needs is based on:

1. Biological and physiological needs: air, food, drink, shelter, warmth, sex, sleep, etc.

2. Safety needs: protection from the elements, security, order, law, stability, etc.

3. Needs related to love and belongingness: friendship, intimacy, trust and acceptance, receiving and giving affection and love, affiliating, being part of a group (family, friends, work).

4. Esteem needs: self-esteem, achievement, mastery, independence, status, dominance, prestige, managerial responsibility, etc.

5. Cognitive needs: knowledge and understanding, curiosity, exploration, the need for meaning and predictability.

6. Aesthetic needs: appreciation and search for beauty, balance, form, etc.

7. Self-actualization needs: realizing one's personal potential, self-fulfillment, seeking personal growth and peak experiences.

8. Transcendence needs: helping others to achieve self-actualization (Maslow 1970; McLeod 2016; Maslow \& Lowery 1998).

This article aims to underline that the introduction of the transcendence needs plays a key role in life motivation for older people.

The hypothesis comes from a contrast to the common narrative that when people grow old and retire, they have economic independence, they hold a social role, and they should take care of their health as they are frail and weak. From personal observations, it seems that older people are focused on something more than their basic needs - something spiritual, to improve their quality of life.

This should lead to a change in the approach to the care of the elderly and accentuate the selfactualization and esteem needs outside of the overtly emphasized physiological care (Majercsik 2005).

\section{Psychological and cultural aspects of aging}

Do people in different countries age differently?

From personal observations, the way people age in Denmark is not the same as in Italy. In Scandinavian countries, the government strategy focuses more on making life independent for the elderly, allowing them to live in their own houses. 
Denmark has developed a wide range of services for the elderly - home help, home nursing, adult day care centers, day nursing homes, and sheltered housing - in order to lead older people towards a more independent lifestyle (Raffel \& Raffel 1987).

This system is totally unknown in Italy, where the social conditions are not as good as in northern Europe. There are many economic deficits in Italy, and the level of assistance changes from region to region. The family is the first line of help for older people, giving them care when they are too weak to live alone (Bernabei, Landi, \& Zuccalà 2002).

Relevant differences also exist between the cultures of the east and west. Asian societies are built on the Confucian value of filial piety and the practice of ancestor worship, both of which are thought to promote positive views of aging and respect for older adults (Davis 1984; Sher 1984; Ho 1994; Sung 2001).

Western societies, in contrast, were thought to be youth-oriented and to think about the aging process and the elderly in a more negative way (Palmore 1975).

The role of aging for indigenous Americans is much different because of the Shamans. The Shaman is an old man who is able to talk to spirits and souls. He is a healer, contributing something to society that younger people cannot. The role and practice of the Shaman is also very physical as he develops dances and trances. The Shaman heals and leads the community, and thus the aging individual represents an element of counterpower. In this kind of society, older people are not a burden, but a resource (Eichberg 2000).

The social representation theory (Moscovici 1988) underlines how views of aging are strongly related to a form of shared cultural representation.

This could lead us to think about how life in aging people is affected by common narratives and prejudices more than the biological process.

\section{Pilgrimage cases}

Awilda Verdejo - A pilgrimage to discover oneself

Awilda Verdejo is an opera singer. At the age of 70 , she decided to have an extraordinary experience, a "walk," that most teenagers and adults would not even consider because of its distance, about $800 \mathrm{~km}$. However, the singer completed this walk thanks to her intrinsic motivational strength.

Interview: Awilda's story leaves us speechless.

Awilda is a famous opera singer who has performed on the major stages of the world, from the Arena of Verona in Italy to the pyramids in Egypt, and her voice is well known all over the world. Awilda is 73 years old, but looks much younger. I would have never been able to determine her age by her appearance.

At the age of 70, Awilda decided to walk "El Camino" to Santiago de Compostela, a route of $800 \mathrm{~km}$. From her story, we know that she got married at the age of 21 and after that she never invested time in herself. She is a spiritual person and prays often, but she doesn't feel that she belongs to a particular religion.

Despite her husband's insistence to go with her, Awilda was determined to make the journey alone. Along the way, the opera singer had mystical and emotional experiences that touched her deeply. However, her experiences will be considered only from a social point of view in order to stay in line with the main objective of the research.

When asked "Awilda, how do you feel in relationships with other people after the experience of El Camino?" she answered: "I stopped judging! Before El Camino, it was something that I often did, but now, after this experience, when I meet people I say to myself 'You do not know who he is and where he comes from and where he is going!' ... And this makes me feel different in relating with others."

Meeting and socializing with other people has been instrumental in Awilda's journey. It's really interesting to note that Awilda joined the walk to get to know herself better, but then she also had to relate to others, learning to be self-confident and to express herself and her feelings.

Through this experience, she learned that movement is of primary importance: "If you move, you stay young!" she says. "Before starting the journey, I worked hard with a personal trainer, and even though it was difficult for me because of my age, I decided to go all the way because I was really motivated to walk the whole track." 
Awilda would probably never have started practicing physical activity during this period of her life because of her age and lifestyle if it weren't for the very strong motivation she had to walk the pilgrimage. The motivation for the pilgrimage was the starting point for a new, more active, lifestyle for her, both from a social and physical point of view.

Tom Cross - A social pilgrimage

This interview will describe the case of Tom Cross. Mr. Cross walked El Camino at the age of 78 with his wife. He is a U.S. citizen and boasts great shape for his 90 years. Tom belongs to the Episcopal belief. Tom says: "The experience, which began out of curiosity, changed day by day into a spiritual trip, and thanks to the spiritual strength I was able to complete the whole walk despite my back and knee problems, a serious infection on my finger, and colon surgery a few months before the trip.

The doctor who made the surgery said it was crazy for me to have an experience like this only a few months after my recovery, so I sent him a lot of postcards from El Camino. I've never considered my age from a biological point of view, but I've considered it according to what I'm able to do with my body and mind. So El Camino is the proof that I'm younger than my age."

Talking with Tom Cross, you can understand how he is active in social work. He and his wife join the parish as volunteers in many activities. They help children with homework, cook for the homeless, and help ex-prisoners get involved in a social context. They are not the only older people to do this-in fact, Tom talks about some peers who work in the same way and with whom he has great friendships.

It's so easy to observe how the parish is a true social institution that helps people, above all the elderly, to feel alive, socially useful, and not outcast, helping to increase their will to live.

Concetta Russo - Walking to see the Virgin

Concetta Russo was born in Napoli, Italy in 1929. She lived through the period of the Second World War. Now she lives in a little flat, very close to her daughter's. She is very proud of her independence and sometimes enjoys the company of her grandchildren.

Because of her type 2 diabetes and the onset of senile dementia, her daughter visits her every day and takes care of her.

Russo is a Catholic woman. Her grandchildren say that until recent years she used to pray every day, and her routine was to go to church every morning. She also listened to a Catholic program on the radio in the evening.

Now, her grandchildren say, she doesn't go out so often, but until 5-6 years ago, she left home every morning at 6:00, no matter the weather conditions, to attend Mass. This was her main activity, along with assisting disabled people in a social center.

About 7 years ago, the old woman decided to join a pilgrimage in Medjugorie.

"Concetta, your grandchildren say that you don't go out from home anymore. You have had surgery because of anigina pectoris, and you get tired very fast. Were you able to walk the hill to see the Virgin Maria?"

"Sure! When I was there, I was there only to see the Virgin. I was anxious to see her. So I had a stick and slowly I climbed the hill alone, with no help. Here I'm not anxious to go out. I have no motivation to get dressed; I tire easily. There is nothing for me!"

It's clear, then, that the motivation to see the Mother of God pushed her to do something out of the ordinary of her normal lifestyle.

Today, at the age of 86, despite type 2 diabetes, osteoporosis, senile dementia, and other health issues, she says: "I'd like to have a pilgrimage because I've been saving money for my whole life, spending most of it for my children. Now it's time to stop and enjoy my money, to have fun and not to leave it to posterity."

Pilgrimage - Lying to leave

"A lot of older people lie about their health conditions to go on a pilgrimage." This is one of the declarations released by Don Lucio Sembrano, the spiritual father of the Catholic religion, who is employed in the Holy See and is a priest of the Parish in Castellammare di Stabia (Napoli, Italy), Gragnano (Napoli, Italy), and Roma (Italy). 
Don Lucio is very active both from a social and physical point of view. In his career, he has been a missionary in Africa, and he is one of the main organizers of pilgrimages in Jerusalem, Israel.

Don Lucio is interested in the pilgrims' health and asks with great care for information that may be relevant to the journey.

However, considering the importance of the place for the faithful, many of them hide their current health status in order to participate.

The father speaks about an old man, aged 82, who lied about his health and walked alone up to Mount Sinai in the night. He had some very serious cardiovascular problems that he revealed to the priest only after the trip.

Maybe nobody would think that an old man, aged 82, with a high risk of cardiovascular disease, could have walked up such a hard hill in the night, alone. But his motivation was so strong that it pushed him to risk his life.

Don Lucio says this happened more than once, and they've had to send back home the bodies of old people who died during the journey. This is really sad but it also gives us the understanding that old people, if they have a very strong motivation, can push their energy to the limit.

From these experiences we can understand that if older people have the motivation, they may push themselves to risk their lives; otherwise, they may remain depressed, joining the vicious cycle of physical inactivity. Low motivation, low physical activity, and sarcopenia increase the risk of sedentary behaviors and related diseases, including disability and death.

Il Profeta - Pilgrimage is "una cosa perosnale"

This interview was given in a little city in the south of Italy called Gragnano, close to Napoli. It is a complex city, as most of them are in the south, where there are, in theory, current laws dictated from the government that are related to some traditional laws from the last century that are still valid for people.

The interviewed man has a real name, but he prefers to introduce himself as "the Prophet." In the south of Italy, it is very common to identify people with a nickname or family name.

"Who is your father?" Before saying anything, the Prophet asks which family I belong to. He doesn't need to know who I am and what I do, but rather who my father is. After ascertaining my local origins, he says "I'm 87 years old, and I've been organizing pilgrimages to Lourdes since 1970. The first time I was there for a personal experience, then I decided to go there every year as volunteer, and now that I am old I need the help of volunteers."

Despite his age, the Prophet joins the pilgrimage to Lourdes every year.

$\mathrm{He}$ is an old man with a tired face and a trembling voice. Nonetheless, he spends most of his day-time in the parish performing different jobs.

He gives the following speech: "There are some people of my age who are, let's say, disabled. But when they hop on the train for the trip, they change. They start walking very fast, back and forth. When you are in the train, everything changes. It's only you, the trip, and the pilgrimage. You need to socialize, otherwise it will be a lonely trip, and this is something personal. Everyone can choose how to have this experience, more or less social. Honestly, I prefer socializing, and most of the time we make a kind of little family that is always together for the whole journey. Socializing in this context is not so difficult, and most old people are usually at home alone and have no one to talk with. People change on the pilgrimages."

As we can see, the interview is not very long. The subject is reserved, and it would have been almost impossible to interview him if the author hadn't been born there and if he hadn't been introduced by the priest.

It's interesting to note that Awilda and Tom are the same age as the old man from Gragnano, more or less, but it would have been very difficult to guess their age based on appearances. However, for the Prophet, the weight of the passing years was much more evident. Thus maybe we can consider the possibility of a link between social involvement and self-care. Care is not only related to physical diseases, which do not seem to be considered very much by older people; there is also care for psychophysical wellness! Being socially active helps people take care of themselves. 
The role of narrative in science

Very often qualitative researchers complain that what they do does not have an impact. "We don't count, because we don't count!" (Brinkmann 2012).

But is narrative so far from reality? How can narrative help scientific research?

What is narrative? The answer could be: Discourses with a clear sequential order that connects events in a meaningful way for a definite audience and thus offers insights about the world and/or people's experiences (Hinchman 1997).

Narratives help constitute our realities and modes of being. We organize our experiences through and into narratives and assign meaning to them through storytelling. Narratives help guide action and are a psychosocio-cultural shared resource that gives substance and texture to people's lives.

The expectations, fantasies, and emotions we have of life form pictures. These pictures can enter into our everyday language while simultaneously becoming the base for the practical dimensions of our life management and its social organization (Eichberg 2000).

Narrative studies and physiological studies are often divided. Nonetheless, in the holistic idea of the human being, it would be useful to try to build a bridge between narrative and physiology.

The human being is a complex one - the mind influences the body and the body can affect the mind.

The body's performance can be tested in a very concrete and practical way, while the mind's activity is not totally accessible. One efficient method of access is narrative.

The success of narrative is well known in psychotherapy.

Though in the past psychotherapy models were often pitted against one another, there have recently emerged reports of a range of integrative models sharing an emphasis on recovery and a number of conceptual elements. These shared elements include paying attention to the importance of interpersonal processes, personal narrative, and metacognition (Hamm \& Leonhardt 2016).

\section{Move your body to pray to your God}

Religion, physical activity, and sport seem to belong to two different worlds, walking on two parallel lines that will never join and have no point in common. In reality, this isn't true.

The Greeks participated in the Olympic Games as a religious celebration in the city of Olympia. As in the modern age, they were organized every four years and, because of the importance of the Games, all wars were interrupted while they were being held. Some African tribes, such as the Ewe in Ghana, use dancing to celebrate their gods.

The book of Bruce Chatwin, The Songlines, describes how the aboriginals in Australia hand down songs and dances that represent the creation myth and imaginary maps of the land. According to the aboriginal culture, singing to the land brings it to life.

In the south of Italy, the "Tarantella" dance, performed on some religious holidays, is still common.

According to some experts, the name "Tarantella" comes from "taranta," a local word in the southern regions for the "tarantola" or Lycosa tarentula, a poisonous spider very common in southern Europe. The Tarantella dance is related to the treatment for the spider's bite. The tradition links to the different effects of the spider's poison, changing according to local beliefs: sadness, convulsions, mental disease, restlessness, pain, and death.

Anyone who was bitten by the "tarantola" (but also by scorpions or other insects) tended to have an exaggerated dynamism and applied for some kind of music therapy, which was really effective in the holiday celebration of St. Pietro and Paolo, as they believed that sweating during the dance would extract the poison. It's important to mention the masterpiece "La terra del rimorso" (De Martino 1961) when speaking about the phenomenon of tarantism in Italy.

The Tarantella and other dances were developed in Europe in the Middle Ages, and they took the name of "dancing mania." They were rites mixed with magic and folklore traditions that aroused the concern of the Church, which believed that the dancers were taken by evil spirits. Today, modern science and psychology 
tries to give other meanings to this phenomenon, calling it a collective neurosis. However, due to the sudden disappearance of the phenomenon, there is a cloud of mystery that remains over it.

Nowadays, there are some dances related to religious celebration, such as in the gospel chorus, that have mostly developed in the U.S.

Sometimes, sport and religion have been in conflict with each other, as in Germany, where yoga was considered a suspicious activity by Christian authorities because of its link with Indian religion (Schmidt 1967).

It's clear that there is a strong relationship between the body and religion. In fact, in the celebration of the Catholic Mass, the body is an instrument of prayer: you can pray on your knees, standing, or sitting, according to the liturgy, and in the Eucharistic celebration, the Body of Christ becomes bread to enter physically into the body and soul of believers. If the link between physical activity and religion is not limited to the prohibition, punishment, fear, and mortification of the body, we can open the topic of how religion can be lived through playing. In games and recreation, humans are shown to be poets building another world (Eichberg 2016). When it comes to pilgrimages, as Prof. Eichberg emphasizes, it's interesting to see the difference between the serious ritual ceremony and the tourist attraction. This dualism is really a big problem in some pilgrimages, such as the one of Dajia Matsu in Taiwan. The pilgrimage requires walking $300 \mathrm{~km}$ through more than 100 temples and involves a huge number of people that take part in holding the statue of Mazu, god of the sea.

The pilgrims come from one of the most technologically advanced societies in the world. They go to their celebration by bike, by skateboard, or in wheelchairs, if they are disabled, in order to take part in this ceremony with fireworks, songs, theater events, and erotic dances (Wong 2013). It is obvious that the involvement of so many pilgrims has some economic benefits, and thus it loses some of its religious meaning along the way.

\section{REFERENCES}

Bernabei, R., Landi, F., \& Zuccalà, G. (2002). Health care for older persons in Italy. Aging Clin Exp Res.,14(4), 247-51. PMID: 12462368. Retrieved on 20/05/2017 from: https://www.ncbi.nlm.nih.gov/pubmed/12462368

Brinkmann, S. (2012). Qualitative research between craftsmanship and McDonaldization. A keynote address from the 17th Qualitative Health Research Conference. Qualitative Studies, 3(1), 56-68.

Cherry, R.L. \& Davis-Friedmann, D. (1984). Long lives: Chinese elderly and the Communist Revolution. Contemporary Sociology, 13(3), 280. DOI: 10.2307/2067562.

De Martino, E. (1961). la terra del rimorso. Contributo a una storia religiosa del Sud, Milano, Il Saggiatore.

Eichberg, H. (2000). Life cycle sports: On movement culture and ageing. In J. Hansen \& N.K. Nielsen (Eds.), Sports, Body and Health (pp. 89-104). Odense: Odense University Press. Retrieved on 25/05/2017 from: https://www.google.dk/search?q=Sung+K.+(2001)+Elder+respect\%3A+Exploration+of+ideals+and+forms+in+East+A sia.Journal+of+Aging+Studies. $\% 3$ B 15\%3A13\%E2\%80\%9326+doi\&oq=Sung+K.+(2001)+Elder+respect $\% 3 \mathrm{~A}+$ Explora tion+of+ideals+and+forms+in+East+Asia.Journal+of+Aging+Studies. $\% 3 \mathrm{~B} 15 \% 3 \mathrm{~A} 13 \% \mathrm{E} 2 \% 80 \% 9326+$ doi\&aqs $=$ chrom e..69i57.3425j0j7\&sourceid $=$ chrome\&ie $=$ UTF-

$\underline{8 \# q=\text { Eichberg, },+H .+(2000) .+ \text { Life }+ \text { cycle }+ \text { sports: }+ \text { On }+ \text { movement }+ \text { culture }+ \text { and }+ \text { ageing. }}$

Eichberg, H. (2016). Questioning Play: What Play Can Tell Us About Social Life. London, New York: Routledge.

Hamm, J.A. \& Leonhardt, B.L. (2016). The role of interpersonal connection, personal narrative, and metacognition in integrative psychotherapy for schizophrenia: A case report. Journal of Clinical Psychology, 72(2), 132-41. DOI: $10.1002 /$ jclp.22247.

Hinchman, L.P. \& Hinchman, S.K. (1997). Memory, Identity, Community-The Idea of Narrative in the Human SciencesIntroduction. In S.K. Hinchman (Ed.),

Ho, D.Y. (1994). Filial piety, authoritarian moralism, and cognitive conservatism in Chinese societies. Genetic, Social, and General Psychology Monographs, 120, 347-365. PMID: 7926697. Retrieved on 30/04/2017 from: https://www.ncbi.nlm.nih.gov/pubmed/7926697

Kosiewicz, J. (2004). Wędrówki religijne jako forma turystyki aktywnej/Religious travel as a form of active tourism/. In J. Kosiewicz (Ed.), Filozoficzne aspekty kultury fizycznej $i$ sportu /Philosophical aspects of physical culture and sport/ (pp. 407-416). Warszawa: Wydawnictwo BK.

Majercsik, E. (2005). Hierarchy of needs of geriatric patients. Gerontology, 51(3), 170-3. DOI: 10.1159/000083989. 
Maslow, A.H. (1943). A theory of human motivation. Psychological Review, 50, 370-396.

Maslow, A.H. (1970). Religions, Values, and Peak Experiences. New York: Penguin.

Maslow, A.H. \& Lowery, R. (Eds.). (1998). Toward a Psychology of Being (3 ${ }^{\text {rd }}$ ed.). New York: Wiley and Sons.

McLeod, S.A. (2016). Maslow's Hierarchy of Needs. Retrieved from www.simplypsychology.org/maslow.html

Moscovici, S. (1988). Notes towards a description of social representations. European Journal of Social Psychology, 18, 211-250. DOI: 10.1002/ejsp.2420180303.

Palmore, E. (1975). What can the USA learn from Japan about aging? Gerontologist, 15, 64-67. PMID: 1110012.

Raffel, N.K \& Raffel, M.W (1987). Elderly care: Similarities and solutions in Denmark and the United States. Public health rep. 102(5), 494-500. PMCID: PMC1477908. Retrieved on 15/05/2017from: https://www.ncbi.nlm.nih.gov/pubmed/3116579

Schmidt, W. (1967). Yoga in Deutschland. Verbreitung, Motive, Hintergründe. Berlin -West: Kreuz-Verlag.

Sher, A. (1984). Aging in Post-Mao China: The Politics of Veneration. Boulder, CO: Westview Press.

Sung, K. (2001). Elder respect: Exploration of ideals and forms in East Asia. Journal of Aging Studies, 15, 13-26. Retrieved on 15/05/2017 from:

http://www.academia.edu/14328305/Elder_respect_exploration_of_ideals_and_forms_in_East_Asia

Wong, H.M. (2013). Mazu mania: Free food, great parties. Wait, this is a religious festival? Retrieved on 27/04/2017 from: http://travel.cnn.com/taiwan-mazu-religious-festival-pilgrimage-226351/

AUTHOR'S ADDRESS: $\quad$ Danilo Contiero

University of Rome

Foro Italico

Lauro de Bosis 6

00135 Roma, Italy

E-mail: d.contiero@studenti.uniroma4

Received: 10 January 2017; Accepted: 24 February 2017 